\title{
Endolacrimal laser assisted lacrimal surgery
}

Klaus Muellner, Elisabeth Bodner, Geva E Mannor, Gerald Wolf, Thiemo Hofmann, Wolfgang Luxenberger

Abstract

Aims-To utilise the improved optical qualities of newly developed lacrimal endoscopes and newly miniaturised laser fibres for diagnostic visualisation and laser surgery of the lacrimal system.

Methods-A KTP laser (wavelength 532 $\mathrm{nm}, 10 \mathrm{~W}$ energy) was used for laser assisted dacryocystorhinostomy (DCR) with endolacrimal visualisation in 26 patients. Bicanalicular silicone intubation was placed in all patients for at least 3 months.

Results-After 3-9 months of follow up, the silicone tube in all 21 patients who underwent KTP laser DCR are still patent, three patients have eye watering in extremely cold weather and two required a conventional DCR.

Conclusions-The KTP laser generates enough power to open the bony window in DCR surgery. Precise endolacrimal visualisation via a specially designed miniendoscope is essential for surgical success.

(Br f Ophthalmol 2000;84:16-18)

New lacrimal endoscopes have been developed that are thin enough to be threaded in the lacrimal puncti and canaliculi to enable direct and precise visualisation of the lacrimal passages. These miniendoscopes have been used for diagnostic localisation of various types of lacrimal disease such as mucosal deposits,

Department of Ophthalmology,

University of Graz, Graz, Austria

K Muellner

E Bodner

Department of Ophthalmology, Mount Sinai Hospital, New

York, USA

G E Mannor

Department of Ear, Nose and Throat,

University of Graz

G Wolf

T Hofmann

W Luxenberger

Correspondence to: Klaus Muellner, MD, Department of

Ophthalmology, University

of Graz, Auenbruggerplatz 4, A-8036 Graz, Austria

Accepted for publication 25 June 1999

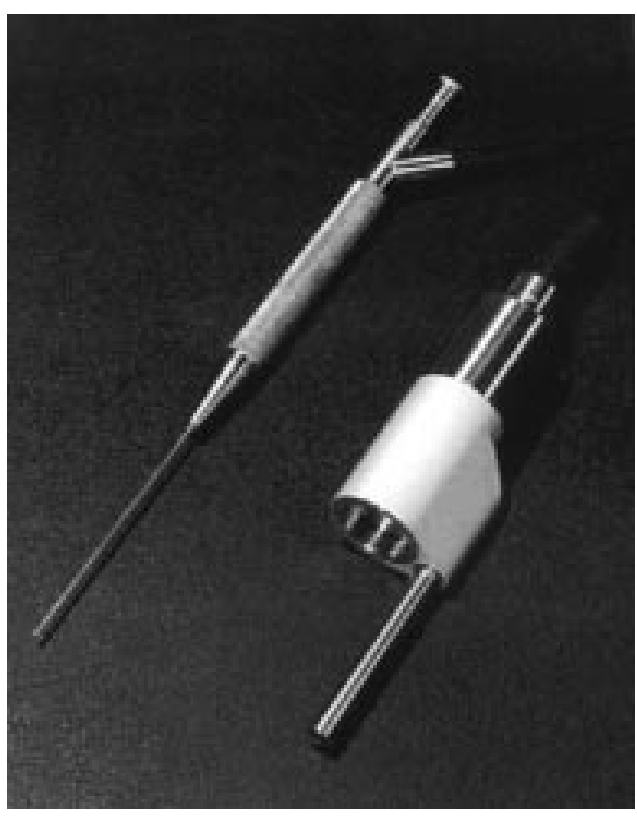

Figure 1 Endoscope: consisting of a metal canula, optic and light fibres. Outer diameter $1.1 \mathrm{~mm}$. inflammatory membranes, strictures, and scar tissue. ${ }^{12}$ In addition, new laser fibres are now thin enough to placed through such miniendoscopes. Thus, endolacrimal (transcanalicular or intracanalicular) laser surgery can be performed while simultaneously viewing the surgery via the same endoscope. We report our experience in treating lacrimal duct disease with these instruments.

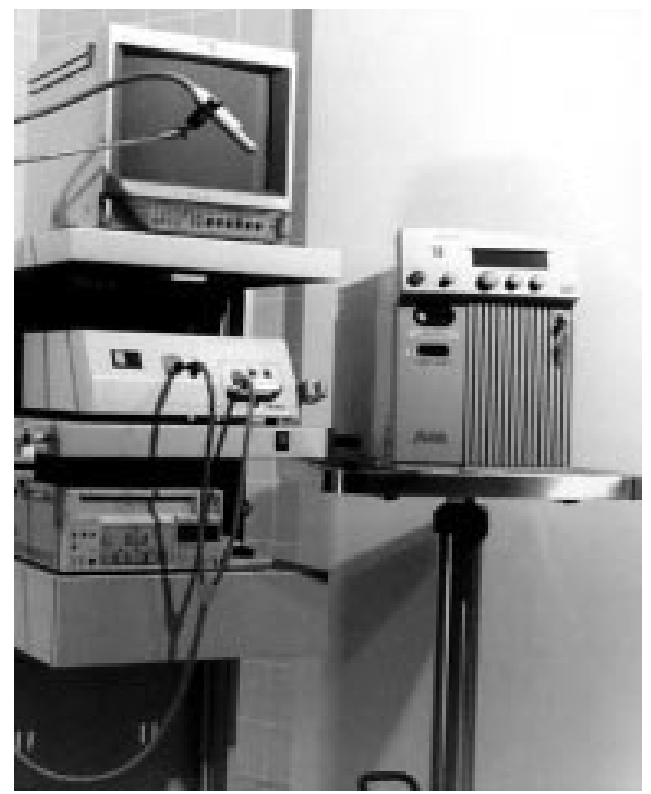

Figure 2 Whole endoscopy system consisting of light source, video recorder, and video screen.

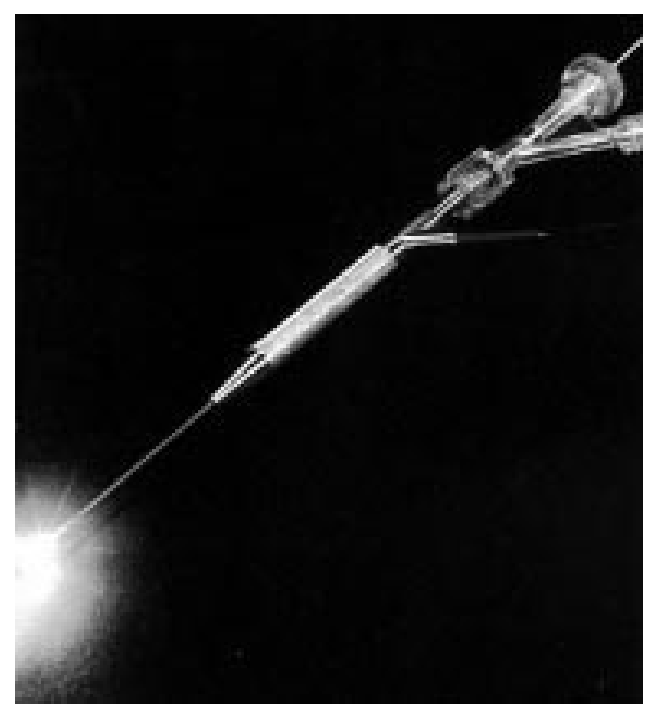

Figure 3 Endoscope with three way adapter for laser fibre, endoscopic light, and light fibres. Laser fibre on top with maximum light. 

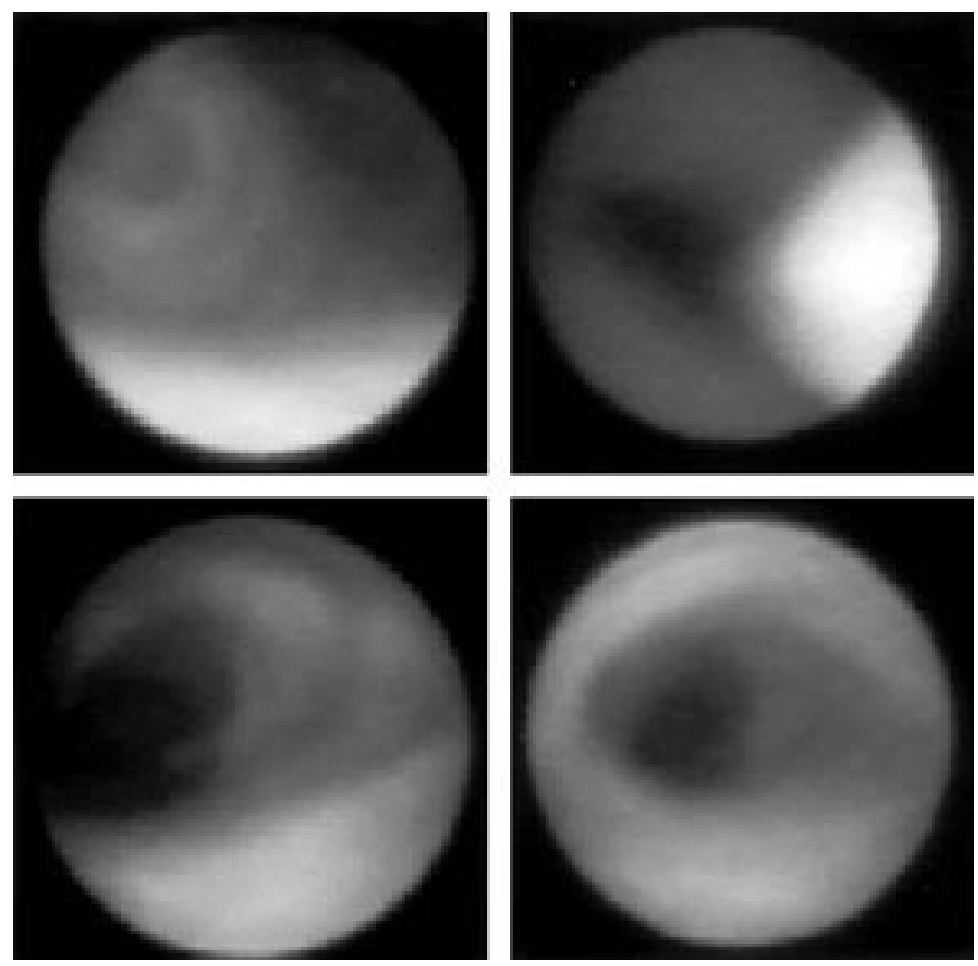

Figure 4 (Top left) Canaliculus occluded through membrane; (top right) laser in situ; (bottom) after opening with laser.

Table 1 Race, sex, and age of patients

\begin{tabular}{ll} 
Race & all white \\
Sex (F/M) & $16 / 10$ \\
Mean age & $55($ SD 11) \\
\hline
\end{tabular}

\section{Patients and methods}

A modified lacrimal miniendoscope was used in all patients (NWL Laserscope, Innsbruck, Austria). Light fibres are arranged in a metal cannula with an outer diameter of $1.1 \mathrm{~mm}$ and an inner diameter of $0.9 \mathrm{~mm}$ which is inside a synthetic covering (Fig 1). The entire unit consists of a xenon light source (Lisa Basic, xenon light source, Medexxa Gmbh, Germany), a video camera (Sony video camera, Sony Gmbh, Japan), with an ocular attachment, and a miniature CCD camera system with a monitor (Sony HR Trinitron) and video recorder (Sony video recorder, SVO $9500 \mathrm{MDP}$ ) (Fig 2). The KTP laser (NWL Laserscope) consists of a $0.3 \mathrm{~mm}$ thick flexible laser fibre surrounded by a synthetic coat. This laser emits light at $532 \mathrm{~nm}$ with a $\mathrm{Q}$ switched mode in either a single or continuous pulses. The laser cuts while in contact mode and coagulates in near contact mode. Its maximum energy is 10 W. A modified lacrimal probe with three ports was used. The laser fibre is inserted via the central port, while the miniendoscope is placed
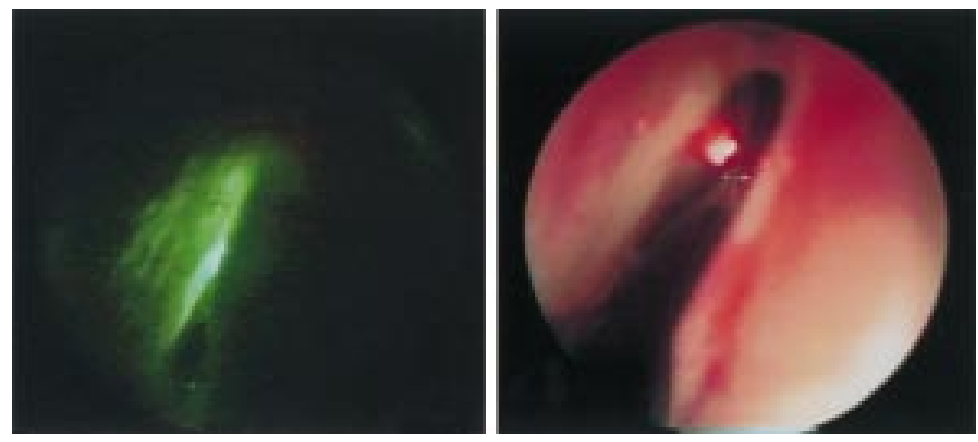

Figure 5 Transcanalicular laser DCR seen from the nose, left: green light during laser procedure; right: laser after penetration through lacrimal sac, bone, and nasal mucosa.

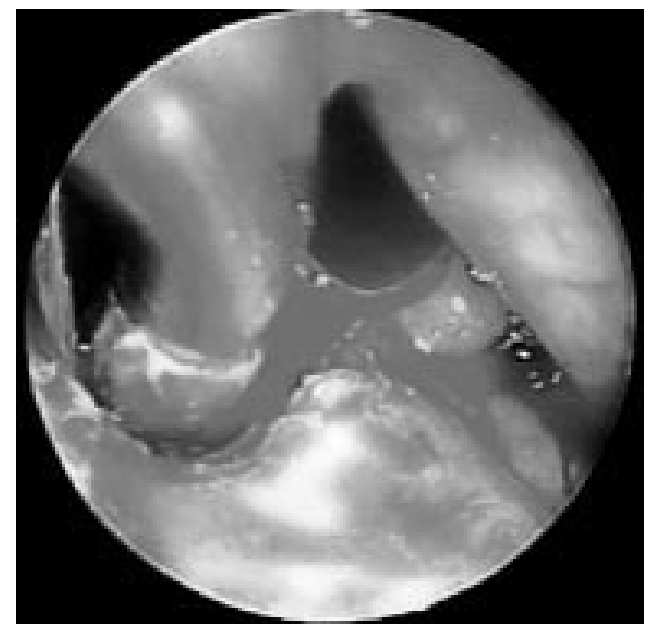

Figure 6 Nasal endoscopy: metal canula (diameter 3 $\mathrm{mm}$ ) from assisting ENT doctor in bony window created by laser.

via a side port (Fig 3). Irrigating fluid flows through the other side port. Twenty six patients with endonasally and endolacrimally verified stenosis of the lacrimal sac or nasolacrimal duct (NLD) were treated with the KTP laser. They all complained of epiphora and had thick mucus or purulent discharge expressible from the lacrimal sac. The canalicular stenosis was localised with the lacrimal endoscope. The colour, condition of canalicula and the lacrimal sac, contour of the submucosa, and extent of the scar tissue or stenosis at the lacrimal duct were assessed.

Dacryocystorhinostomy (DCR) was performed under general anaesthesia. After irrigating and cleansing the lacrimal drainage system the lacrimal probe was placed with the laser fibre tip and the endoscope advanced to the lateral wall of the lacrimal sac. Correct positioning of the instruments was verified via endonasal and endosaccal visualisation (Fig 4). A bony osteotomy of at least $5 \mathrm{~mm}$ in diameter was achieved with 6-10 W of energy (Fig 5). The total amount of energy required was 124432 (average 256) W. Surgery lasted 3-10 (average 5) minutes. Bicanalicular silicone intubation was performed and the tube was left in place for 3-6 months.

\section{Results}

No patients experienced any bleeding or infection. No other complications were noted. In the 26 patients with lacrimal sac or duct (NLD) obstruction, greyish-white thick fibrous bands were noted.

Within 3-6 months of follow up, 21 treated for lacrimal sac or duct (NLD) obstruction remained free of symptoms and their lacrimal duct could be easily irrigated. Three of 26 patients have much improved symptoms but tear intermittently in extremely cold weather. Endonasal visualisation of these patients reveals a patent bony osteotomy measuring 3-5 $\mathrm{mm}$ in diameter (Fig 6). Two patients required a conventional DCR because of tearing and blurred symptoms. Endoscopic evaluation showed a restenosis of the mucosa and bony hole. 


\section{Discussion}

Dutton and Holck described a holmium laser for opening complete or incomplete canalicular stenosis. ${ }^{3}$ In their opinion, their 57\% success rate justified this minimally invasive therapy, especially when compared with alternatives such as Jones tube surgery or canaliculodacryocystorhinostomy. Patel et al reported the use of a Nd:YAG laser to open obstructions after external DCR. ${ }^{4}$ Their $46 \%$ success rate is significantly lower than after a external revision DCR. Their intracanalicular revision laser DCR took 25 minutes longer than the conventional external revision. Dutton and Patel performed transcanalicular laser surgery without directly visualising the lacrimal drainage system and its mucosa through a lacrimal endoscope. ${ }^{34}$ In our opinion, a safer and better choice of the appropriate surgical procedure can be made through the intraoperative use of a lacrimal endoscope. Although preoperative irrigation and probing allow for indirect diagnosis, they may also lead to the wrong choice of therapy.

While using the miniendoscope to localise the lacrimal obstruction and make the correct diagnosis, we also wanted to utilise the endoscopic unit as a therapeutic tool.

In his report about the possible use of lasers for the lacrimal drainage system, Bartley describes different types of lasers used to perform DCR. ${ }^{5}$ In his opinion, the considerable costs and much lower success rate of an endonasal DCR are significant disadvantages because the outcome of any new DCR procedure must always be compared with the $90 \%$ success rate of conventional, external DCR. Christenbury and Massaro et al described initial attempts at transcanalicular DCRs. ${ }^{67}$ Bone penetration and small bony osteotomy were the main problems. Christenbury was unable to penetrate the bone using a laser with an energy of $3.2 \mathrm{~W}$, while Massaro et al found the tissue to be damaged too much with an energy of $16 \mathrm{~W}$. In cadavers, Levin and Stormogipson were able to create a bony win- dow of $6 \times 6 \mathrm{~mm}$ with a KTP laser. ${ }^{8}$ This report is supported by Gonnering who successfully performed 12 endonasal DCRs with a KTP laser. ${ }^{9} \mathrm{He}$ was able to achieve a bony window of $5 \times 6 \mathrm{~mm}$ using energy of between 5 and $7 \mathrm{~W}$. We used a KTP laser fibre threaded through the canaliculus with simultaneous lacrimal endoscope visualisation in 26 patients. Twenty one of 26 of our patients had complete resolution of preoperative epiphora and three patients have only intermittent epiphora in severely cold weather. Only two patients required reoperation. Owing to its particular wavelength and energy, the KTP laser can safely create a bony window within a short period of time.

Although our follow up is short and the numbers of patient small, we are encouraged by our results. The success rates reported herein are satisfactory, especially since this allows for minimally invasive and rapid outpatient surgery. As described by Hartikainen ${ }^{10}$ the success decrease from $90 \%$ to $60 \%$ after 1 year follow up - a longer follow up and a larger number of patients will be necessary for future studies.

1 Emmerich KH, Meyer-Ronsenberg HW, Simkl P. Endoskopie der Tränenwege. Ophthalmologe 1997;94:732-5.

2 Müllner K. Tränenwegsendoskopie-Erster Erfahrungsbericht. Ophthalmologe 1997;94:736-8.

3 Dutton JJ, Holck DEE. Holmium laser canaliculoplasty. Ophthalmic Plast Reconstr Surg 1996;12:211-7.

4 Patel BCK, Phillips B, McLeish WM, et al. Transcanalicular Nd:YAG laser for revision of dacryocystorhinostomy. Ophthalmology 1997;104:1191-7.

5 Bartley GB. The pros and cons of laser dacryocystorhinostomy. Am f Ophthalmol 1994;117:103-6.

6 Christenbury JD. Translacrimal laser dacryocystorhinostomy. Arch Ophthalmol 1992;110:170-1.

7 Massaro BM, Gonnering RS, Harris GJ. Endonasal laser dacryocystorhinostomy. Arch Ophthalmol 1990;108: 1772-6.

8 Levin PS, Stormogipson DJ. Endocanalicular laser-assisted dacryocystorhinosotmy. Arch Ophthalmol 1992;110:148890.

9 Gonnering RS, Lyon DB, Fisher JC. Endoscopic laserassisted lacrimal surgery. Am f Ophthalmol 1991;111:1527.

10 Hartikainen J, Grenman R, Puukka P, et al. Prospective randomized comparison of external dacryocystorhinostomy and endonasal laser dacrycystorhinostomy. Ophthalmology 